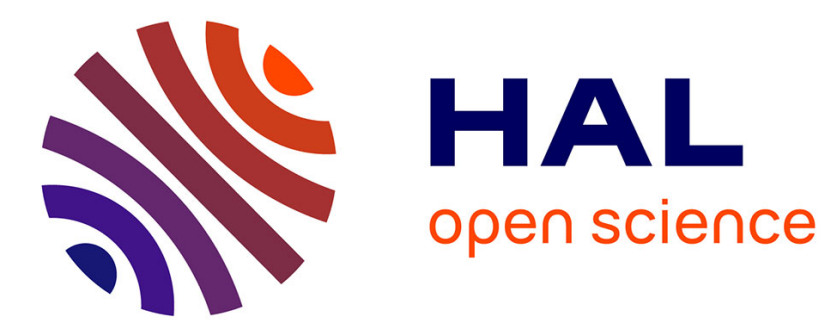

\title{
$S$ velocity reversal in the mantle transition zone
}

L Vinnik, Véronique Farra

\section{To cite this version:}

L Vinnik, Véronique Farra. S velocity reversal in the mantle transition zone. Geophysical Research Letters, 2006, 33 (18), 10.1029/2006GL027120 . insu-01285681

\section{HAL Id: insu-01285681 https://hal-insu.archives-ouvertes.fr/insu-01285681}

Submitted on 10 Mar 2016

HAL is a multi-disciplinary open access archive for the deposit and dissemination of scientific research documents, whether they are published or not. The documents may come from teaching and research institutions in France or abroad, or from public or private research centers.
L'archive ouverte pluridisciplinaire HAL, est destinée au dépôt et à la diffusion de documents scientifiques de niveau recherche, publiés ou non, émanant des établissements d'enseignement et de recherche français ou étrangers, des laboratoires publics ou privés. 


\title{
$S$ velocity reversal in the mantle transition zone
}

\author{
L. Vinnik ${ }^{1}$ and V. Farra ${ }^{2}$ \\ Received 12 June 2006; revised 16 August 2006; accepted 23 August 2006; published 29 September 2006.
}

[1] The transition zone differs from the rest of the mantle by high positive $\mathrm{P}$ and $\mathrm{S}$ wave velocity gradients. However, by applying $\mathrm{S}$ receiver function technique to recordings of about 50 globally distributed stations, in 7 regions we obtain evidence of negative discontinuity at a depth around $500 \mathrm{~km}$. Four of these regions correspond to the well known hotspots. No other hotspots are sampled by our observations at this depth. Our modeling suggests that the negative discontinuity is hardly an effect of anisotropy of wadsleyite. More likely, it is caused by isotropic $\mathrm{S}$ velocity reduction of around $0.2 \mathrm{~km} / \mathrm{s}$. Origin of the low velocity can be related to enhanced water content in wadsleyite. Citation: Vinnik, L., and V. Farra (2006), S velocity reversal in the mantle transition zone, Geophys. Res. Lett., 33, L18316, doi:10.1029/2006GL027120.

\section{Introduction}

[2] The mantle transition zone (MTZ) differs from the rest of the mantle by high positive $\mathrm{P}$ and $\mathrm{S}$ wave velocity gradients, which are caused mainly by a series of phase transformations. This depth range is notable by a low resolution and poor correlation of the global tomographic models. To understand processes in the MTZ, seismic studies with a better resolution are required. Application of $\mathrm{S}$ receiver function (SRF) technique [Farra and Vinnik, 2000] provided first evidence of a negative discontinuity in the upper MTZ in the vicinity of two hotspots: Afar [Vinnik et al., 2004] and Iceland [Vinnik et al., 2005]. Here we present a new series of seismic observations related to this discontinuity.

[3] Observations of the negative discontinuity are important, because the low S wave velocity in the MTZ can be related to the presence of water, which may have a large effect on processes in the mantle. Recent studies of the nominally anhydrous wadsleyite and ringwoodite indicate that they may contain up to about $2.0 \mathrm{wt} \%$ of $\mathrm{H}_{2} \mathrm{O}$ [Hirschmann et al., 2005]. The average content of water in the MTZ, though generally unknown, is, very likely, much lower than the maximum, but if it locally reaches $1 \mathrm{wt} \%$, the $\mathrm{S}$ velocity of the hydrous phases becomes several percent lower than the anhydrous velocity [Smyth and Jacobsen, 2006].

[4] Like in the previous studies, our analysis is based on observations of the Sdp (converted from S to P at a depth d) phases that are detected using SRFs. The details of the technique can be found elsewhere [Farra and Vinnik, 2000], and here we present only the essentials. The threecomponent seismogram is decomposed into P and SV components. The SV axis corresponds to the principal S particle motion direction in the wave propagation plane. The $\mathrm{P}$ axis,

\footnotetext{
${ }^{1}$ Institute of Physics of the Earth, Moscow, Russia.

${ }^{2}$ Institut de Physique du Globe de Paris, Paris, France.
}

Copyright 2006 by the American Geophysical Union. 0094-8276/06/2006GL027120 which is normal to SV in the same plane, is optimal for detecting the Sp converted phases, because the P component of the record is free from the $\mathrm{S}$ wave energy. The $\mathrm{P}$ components of many seismic recordings are deconvolved by the SV components of the $\mathrm{S}$ waves and stacked to reduce noise. Slant stacking facilitates detection of seismic phases, the slowness of which differs from that of the parent phase.

[5] The SRF method is relatively new, and its advantages and limitations still are debated. In the data there is a simple and robust indicator of quality of the SRF: a detection of the Sp phase from the global $410 \mathrm{~km}$ discontinuity implies that the method is sensitive enough to detect the $\mathrm{S}$ velocity contrast of around $0.2 \mathrm{~km} / \mathrm{s}$ at this depth. Moreover, the largest depth sampled by the SRF depends on epicentral distance. The Sp phase from a negative discontinuity in the MTZ becomes observable at a smaller epicentral distance than the Sp phase from a positive discontinuity at this depth, and stacking in a broad distance range may result in a larger signal from the negative discontinuity.

[6] $P$ receiver function (PRF) technique is an alternative method for mapping seismic boundaries in the MTZ. However, in the PRFs indications of a negative discontinuity were never found. Most of these studies were conducted at the periods from 2 to 5 seconds, $\sim 3$ times shorter than the periods of $\mathrm{S}$ receiver functions. A gradational boundary can be transparent at short periods in the PRF but detectable at longer periods in the SRF. Anelastic attenuation is another reason: the Ps phases can be a few times smaller than the Sp phases, owing to a high attenuation of the $S$ waves relative to P. The most obvious advantage of the SRF over PRF stems from the fact that, unlike the Ps phases, the Sp phases from deep discontinuities are separated in time from reverberations of shallow origin.

\section{Data and Results}

[7] The data are extracted from a set of SRFs of more than 50 globally distributed seismograph stations (Figure 1) and portable groups of stations. Those stations, where we could not obtain SRFs of good quality, are not shown in Figure 1. The number of stacked receiver functions for each station in Figure 1 (at least several tens) is sufficient for obtaining a high signal/noise ratio: the normalized amplitudes of the signals of interest are around 0.03, whereas the RMS amplitude of noise is not more than 0.007 (Table 1). New observations of seismic signals from the negative discontinuity in the MTZ are made at stations BGCA and BNG in central Africa, TUC and CMB in the western USA, BJT in China, YKW3 and SCHQ in Canada and ALE and DSS in Afar.

[8] The recordings of neighboring stations BGCA and BNG were processed as a single data set. For our sign convention, negative polarity corresponds to positive discontinuity. The stack for the back azimuths around $78^{\circ}$ (Figure 2a) is characteristic of the "normal" mantle: the only robust 


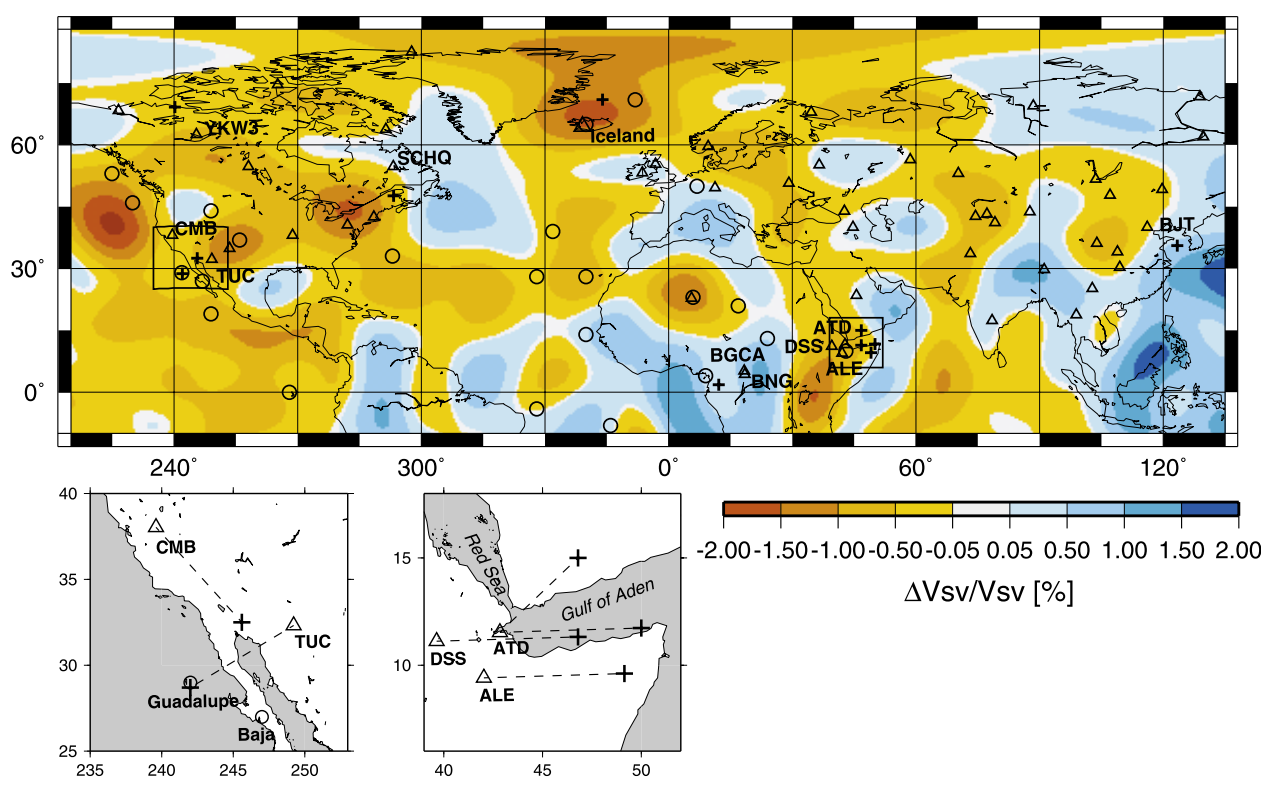

Figure 1. Map of the northern hemisphere with seismograph stations (triangles), piercing points (crosses), hotspots (circles, modified from Duncan and Richards [1991]) and S velocity at a depth of $525 \mathrm{~km}$ [Ritsema and van Heist, 2000]. Stations with indications of the negative discontinuity in the MTZ are marked by station codes. In Iceland the data are obtained at a group of stations [Vinnik et al., 2005]. At the bottom of the figure, Afar and the west of America are shown enlarged; seismograph stations are connected with the piercing points by dash lines. Outside the region shown on the map we have only a few seismograph stations (LBTB and BOSA in south Africa), NWAO (Australia), SPA, SBA and DRV (Antarctica) and MA2 in easternmost Eurasia.

seismic phase in the time window of interest is S410p with negative polarity at $-48 \mathrm{~s}$. However, in the azimuths around $240^{\circ}$ (Figure $2 \mathrm{~b}$ ), the dominant arrival has positive polarity at a time around $-57 \mathrm{~s}$. In our interpretation, this is the Sp phase from a negative discontinuity in the upper MTZ. The SRFs of stations CMB and TUC in differing azimuths (Figures 2c and $2 \mathrm{~d}$ ) sample neighboring regions in the MTZ (Figure 1), and they contain similar signals with positive polarity. To attain a high signal/noise ratio, the recordings of station ALE and DSS were processed jointly. The resulting stack (Figure 2e) is similar to that previously obtained in the same back azimuths (between $67^{\circ}$ and $103^{\circ}$ ) at the neighboring station ATD [Vinnik et al., 2004]. Similar signals are present in the SRFs of stations BJT, YKW3 and SCHQ.

[9] Almost all SRFs in Figure 2 (except 2b) contain a clear S410p phase. The differences in the time of this phase reflect mainly differences in the average epicentral distance (Table 1). In a spherically symmetrical Earth, the theoretical differential slowness of the Sp phase from the upper MTZ is around $0.4 \mathrm{~s} /{ }^{\circ}$. In most cases, the maximum amplitudes of the S410P and of the $\mathrm{Sp}$ phase from the negative discontinuity occur near this slowness. The deviations are caused by noise and lateral heterogeneity of the Earth. In particular, a deviation of $0.2 \mathrm{~s} /{ }^{\circ}$ can be caused by a tilt of around $1^{\circ}$ of the converting interface. The SRFs in Figure 2 contain other interesting arrivals, but they are beyond the scope of our paper.

[10] To construct velocity models of the MTZ, we calculated synthetic SRFs [Vinnik et al., 2004], and searched for the preferred $\mathrm{S}$ velocity profiles by trial and error. The details of the models clearly cannot be determined uniquely, but at this stage we are interested only in the approximate depth range and magnitude of the $\mathrm{S}$ velocity reduction. We assume, that the $410-\mathrm{km}$ discontinuity is located at its standard depth, and perturb IASP91 standard model [Kennett and Engdahl, 1991] above the $410 \mathrm{~km}$ discontinuity to obtain the model with the arrival time of S410p close to that in the actual data. Then we perturb S velocity in the MTZ to reproduce the seismic phase with positive polarity (see example in Figure 3a).

[11] We model the negative discontinuity by a gradational boundary $30 \mathrm{~km}$ thick, although our data cannot distinguish it

Table 1. Parameters of the Recordings

\begin{tabular}{|c|c|c|c|c|c|c|c|c|}
\hline Station & Latitude, deg & Longitude, deg & Number of Events & Distance, deg & Azimuth, deg & Noise & Depth, km & $\delta \mathrm{V}_{\mathrm{S}}, \mathrm{km} / \mathrm{s}$ \\
\hline BGCA & 5.2 & 18.4 & 54 & 88 & 242 & 0.006 & 465 & -0.2 \\
\hline BNG & 4.4 & 18.5 & 31 & & & & & \\
\hline CMB & 38.0 & 239.6 & 69 & 77 & 138 & 0.007 & 500 & -0.3 \\
\hline TUC & 32.3 & 249.2 & 98 & 86 & 241 & 0.006 & 495 & -0.1 \\
\hline ALE & 9.4 & 42.0 & 23 & 83 & 86 & 0.007 & 510 & -0.2 \\
\hline DSS & 11.1 & 39.6 & 38 & & & & & \\
\hline BJT & 40.0 & 116.2 & 81 & 81 & 125 & 0.004 & 465 & -0.2 \\
\hline YKW3 & 62.5 & 245.4 & 122 & 85 & 334 & 0.005 & 485 & -0.3 \\
\hline SCHQ & 54.8 & 293. 2 & 55 & 77 & 181 & 0.007 & 470 & -0.2 \\
\hline
\end{tabular}



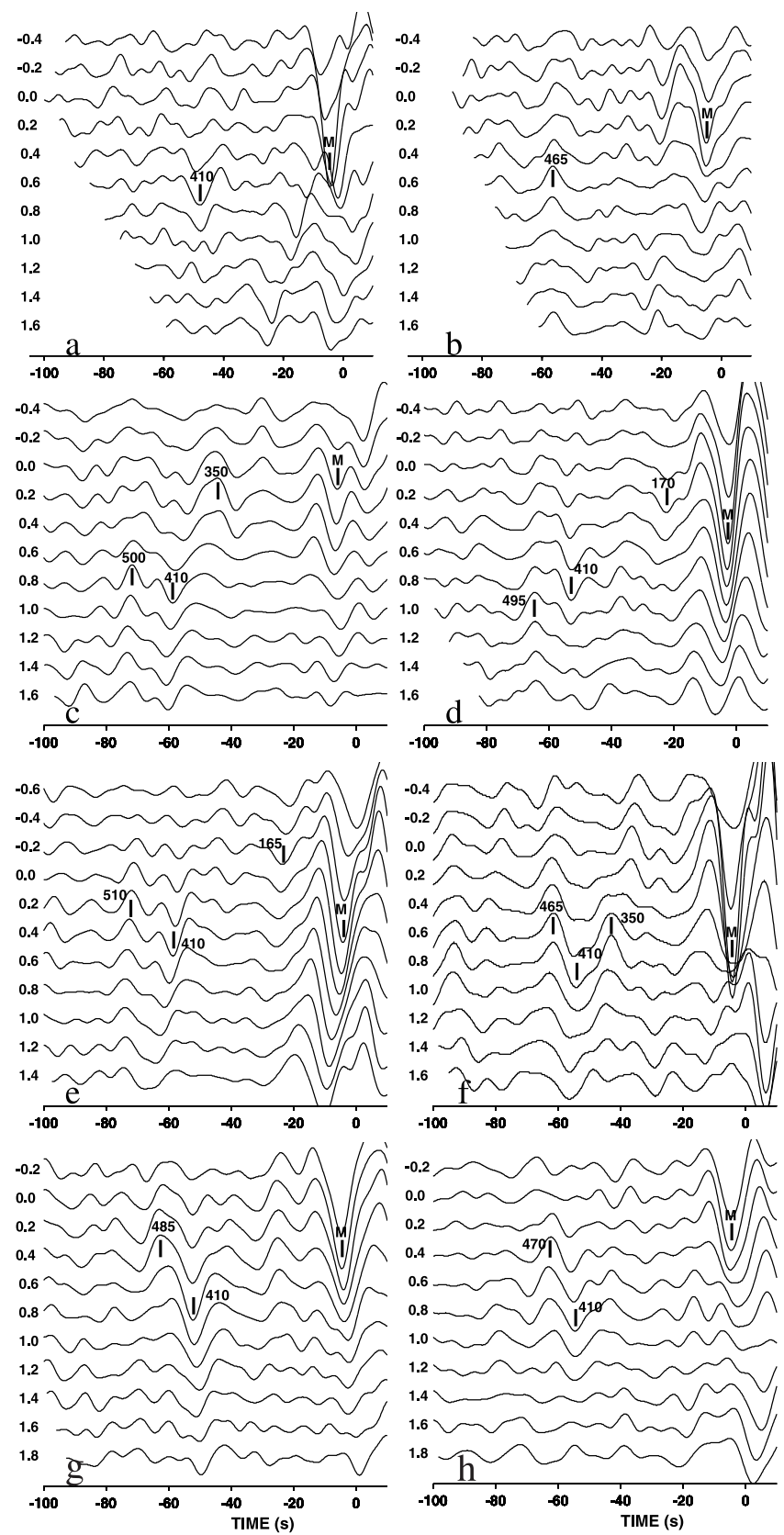

Figure 2. Stacked $\mathrm{S}$ receiver functions for seismograph stations BGCA and BNG in back azimuths around (a) $78^{\circ}$ and (b) $240^{\circ}$; stations (c) CMB, (d) TUC, (e) ALE and DSS, (f) BJT, (g) YKW3, and (h) SCHQ. Each trace corresponds to the differential slowness in $\mathrm{s} /{ }^{\circ}$ on the left. The arrivals of the $\mathrm{Sp}$ phases are marked on the traces with the largest amplitudes; the numbers indicate depths of the discontinuities in km; M is for the Moho. For the details see Table 1.

from the sharp discontinuity. A gradational boundary is suggested by the fact, that signals from the negative discontinuity were never identified in short periods in the PRFs (see Introduction). The thickness of the underlying low velocity layer is usually not well constrained, because signals from its lower boundary are not detected with confidence. Among other reasons, this can be an effect of a reduced sensitivity of the method at larger depths. The model of the MTZ thus obtained can be described by the two parameters: depth of the middle of the gradational boundary and $\mathrm{S}$ velocity reduction in the underlying layer relative to IASP91 (Table 1). The accuracy of depth of the middle of the gradational boundary thus determined is not better than $10-15 \mathrm{~km}$; the variations of this depth between 465 and $510 \mathrm{~km}$ (Table 1) may reflect both actual lateral variations and errors of the estimates.

[12] To compare SRFs and PRFs we calculated PRF for station SCHQ in the same azimuth and frequency range as the corresponding SRF (Figure 3b). The time interval of interest between 44 and $70 \mathrm{~s}$ in the PRF is dominated by reverberations and no details within the MTZ can be found with confidence. The P660s phase is probably seen, but its theoretical amplitude is at least twice larger than the expected amplitude of the signal from the negative discontinuity. A similar result is obtained for station TUC. Note that the piercing points of the Sp and Ps phases from a discontinuity in the MTZ are at a distance of several hundred kilometers from each other, and they not necessarily sample the same region in the MTZ.

\section{Anisotropic Models of the MTZ}

[13] Here we try to explain the Sp phase with positive polarity by a mechanism increasing the $\mathrm{S}$ velocity over the discontinuity. Among the volumetrically important minerals of the upper MTZ, wadsleyite crystal shows the largest elastic anisotropy, and deformations lead to a preferred crystal orientation [Tommasi et al., 2004]. We investigate a possibility that the Sp phase with positive polarity is generated at the boundary between anisotropic wadsleyite and practically isotropic ringwoodite [Wenk et al., 2005]. Theoretical seismograms are synthesized by using ThomsonHaskell-Crampin algorithm [Kosarev et al., 1979] for elastic parameters of deformed pyrolite in Table 1 of Tommasi et al. [2004]. These parameters are obtained for the MTZ pressure at ambient temperature, and therefore the related isotropic wave velocities are higher than the actual velocities. To obtain lower velocities, we modified the model. In the modified model, anisotropy is the same, but the velocities are close to the actual velocities in the MTZ $(9.3 \mathrm{~km} / \mathrm{s}$ and $5.07 \mathrm{~km} / \mathrm{s}$ for the $\mathrm{P}$ and $\mathrm{S}$ waves, respectively). The assumed wave slowness is $10 \mathrm{~s} /{ }^{\circ}$. The boundaries between anisotropic and isotropic pyrolite are placed at $410 \mathrm{~km}$ and $520 \mathrm{~km}$ depths; elastic parameters of the isotropic media are those from standard Earth models.
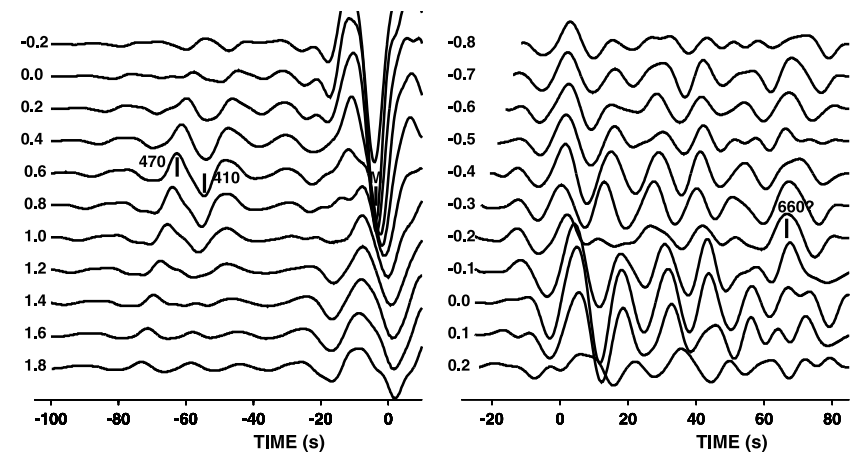

Figure 3. (left) Synthetic SRF and (right) observed PRF for station SCHQ. 

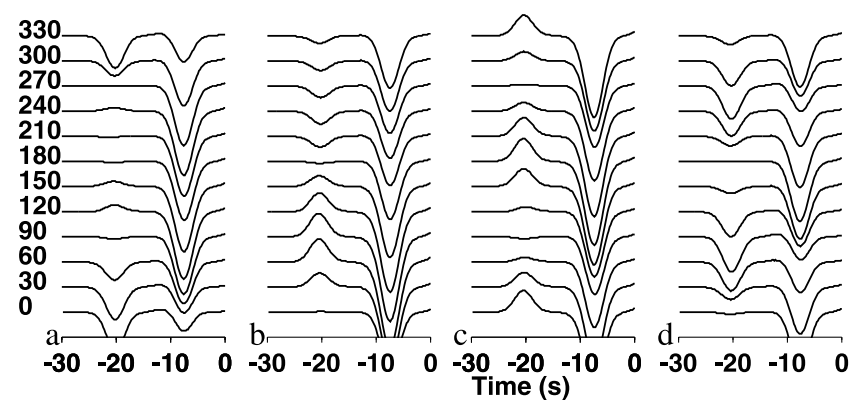

Figure 4. Synthetic P components for deformed wadsleyite: (a) shear in the vertical direction, shear plane is in the azimuth of $90^{\circ}$; (b) horizontal shear plane, azimuth of shear is $90^{\circ}$; (c) horizontal foliation plane, azimuth of lineation is $0^{\circ}$; (d) vertical foliation plane in the azimuth of $0^{\circ}$, lineation is vertical. Origin of the time axis is arbitrary. Numbers attached to the traces are back azimuths in degrees.

[14] The synthetic SRFs (Figure 4) contain the S410p (at around $-10 \mathrm{~s}$ ) and S520p (at around $-20 \mathrm{~s}$ ). The largest amplitudes of the S410p phase are practically those for isotropic medium, and they can be used as a reference. For the vertical shear (Figure 4a), polarity of the S520p phase is opposite to the observed one everywhere, except the two traces, where its amplitude is very small. For the horizontal shear (Figure 4b), the polarity in some azimuths is positive, but the amplitude is less than $30 \%$ of that of S410p, much lower than in the actual data (Figure 2). The elastic parameters of Tommasi et al. [2004] are for relatively low strain. At larger strains the foliation and shear planes are practically parallel. In the case of horizontal foliation plane (Figure 4c), the polarity in some azimuths is positive, but the amplitude is too small. Moreover, similar amplitudes at stations $\mathrm{CMB}$ and TUC in the azimuths differing by roughly $90^{\circ}$ contradict the synthetics. Finally, in the case of vertical foliation plane (Figure 4d), polarity of S520p is always negative. We conclude that the synthetics cannot be reconciled with the actual data mainly due to the large difference in amplitudes.

\section{Discussion and Conclusions}

[15] At several locations we observed seismic phases that, in our interpretation, are converted from a negative discontinuity at a depth between 465 and $510 \mathrm{~km}$. At the negative discontinuity $\mathrm{S}$ velocity decreases with depth by about $0.2 \mathrm{~km} / \mathrm{s}$. The synthetics for anisotropic wadsleyite do not fit the actual SRF, and thus, anisotropy as an explanation for the negative discontinuity seems unlikely.

[16] Locations of the anomalous regions follow a remarkable regularity. Afar and Iceland are classic hotspots. The piercing points for stations TUC and CMB are in the region of Baja and Guadalupe hotspots, which are often referred as one hotspot. The piercing point for station TUC coincides with the Guadalupe. The piercing point for station CMB is located to the north-east of the Guadalupe, but the first Fresnel zone of the Sp phase in the MTZ is a few hundred kilometers in diameter, and we believe that both stations sample the same anomaly of the MTZ. The piercing point for stations BNG and BGCA is near Cameroon hotspot. This hotspot contains a number of volcanic centers along the SW- NE line in the ocean and continental margin. The piercing point corresponds to the middle of the line. The region sampled by the data of station BJT is remarkable by rifting, high heat flow, erosion of the mantle lithosphere and low seismic velocities in the upper mantle [Griffin et al., 1998]. These properties are indicative of a mantle upwelling, which might originate in the MTZ. The piercing points for stations YKW3 and SCHQ are near low S velocity anomalies in the MTZ (Figure 1).

[17] We presented practically all available data on the MTZ beneath hotspots, and out of the four sampled hotspots all display the negative discontinuity. The SRF may sample the MTZ beneath a hotspot only if the seismograph station is at the appropriate distance from the hotspot, and the seismic events are in the appropriate back azimuth. For example, station TAM (coordinates $22.8 \mathrm{~N}, 5.5 \mathrm{E}$ ), without any indication of the negative discontinuity in the MTZ, is located in the Hoggar hotspot, but its SRF samples the MTZ $\sim 700 \mathrm{~km}$ to the west of the station, far from the volcanic centers.

[18] As we already mentioned in the Introduction, if on the average the MTZ is almost dry, a local anomaly of $1 \mathrm{wt} \%$ of water may generate a significant $\mathrm{S}$ wave velocity anomaly, and reduced $\mathrm{S}$ wave velocities are generally indicative of hydration [Smyth and Jacobsen, 2006]. Solubility of water in wadsleyite sharply decreases with temperature [Demouchy et al., 2005], and, if the water content in the MTZ at a low temperature is locally close to saturation, an increase in temperature on the order of $100^{\circ}$ may cause dehydration and melting with a large reduction of $\mathrm{S}$ velocity. This might explain the connection between the low velocity and hotspots. The melt may reside at a depth around $500 \mathrm{~km}$ owing to its neutral buoyancy.

[19] Acknowledgments. This study was supported by the Russian Fund for Basic Research, grant 04-05-64634. We thank Program Interieur de la Terre 'Corne de l'Afrique' of INSU-CNRS for the seismograms of stations ALE and DSS. The seismograms of the other stations were obtained from IRIS DMC. We highly appreciate advice from J.-P. Poirier, S. Karato, P Cordier, D. Mainprice, L. Stixrude, T. Duffy and G. Leahy, and thank two anonymous reviewers for their helpful comments.

\section{References}

Demouchy, S., E. Deloule, D. J. Frost, and H. Keppler (2005), Pressure and temperature dependence of water solubility in Fe-free wadsleyite, $\mathrm{Am}$. Mineral., 90, 1084-1091.

Duncan, R. A., and M. A. Richards (1991), Hotspots, mantle plumes, flood basalts and true polar wander, Rev. Geophys., 29, 31-50.

Farra, V., and L. P. Vinnik (2000), Upper mantle stratification by $P$ and $S$ receiver functions, Geophys. J. Int., 41, 699-712.

Griffin, W. L., A. Zhang, S. Y. O’Reilly, and C. G. Ryan (1998), Phanerozoic evolution of the lithosphere beneath the Sino-Korean craton, in Mantle Dynamics and Plate Interactions in East Asia, Geodyn. Ser., vol. 27, edited by M. Flower, et al., pp. 107-126, AGU, Washington D. C.

Hirschmann, M. M., C. Abaud, and A. C. Withers (2005), Storage capacity of $\mathrm{H}_{2} \mathrm{O}$ in nominally anhydrous minerals in the upper mantle, Earth Planet. Sci. Lett., 236, 167-181.

Kennett, B. L. N., and E. R. Engdahl (1991), Traveltimes for global earthquake location and phase identification, Geophys. J. Int., 105, 429-465. Kosarev, G. L., L. I. Makeyeva, E. F. Savarensky, and E. M. Chesnokov (1979), Influence of anisotropy beneath seismograph station on body waves (in Russian), Izv. Akad. Nauk, Ser. Fiz., 2, 26-37.

Ritsema, J., and H. J. van Heist (2000), Seismic imaging of structural heterogeneity in the Earth's mantle: Evidence for large-scale mantle flow, Sci. Prog., 83, 243-259.

Smyth, J. R., and S. D. Jacobsen (2006), Nominally anhydrous minerals and Earth's deep water cycle, in Earth's Deep Water Cycle, Geophys. Monogr. Ser., edited by S. van der Lee and S. D. Jacobsen, AGU, Washington, D. C., in press. 
Tommasi, A., D. Mainprice, P. Cordier, C. Thoraval, and H. Couvy (2004), Strain-induced seismic anisotropy of wadsleyite polycrystals and flow patterns in the mantle transition zone, J. Geophys. Res., 109, B12405, doi:10.1029/2004JB003158

Vinnik, L. P., V. Farra, and R. Kind (2004), Deep structure of the AfroArabian hotspot by S receiver functions, Geophys. Res. Lett., 31, L11608, doi:10.1029/2004GL019574.

Vinnik, L. P., G. R. Foulger, and Z. Du (2005), Seismic boundaries in the mantle beneath Iceland: A new constraint on temperature, Geophys. J. Int., 160, 533-538.
Wenk, H.-R., G. Ischia, N. Nishiyama, Y. Wang, and T. Uchida (2005), Texture development and deformation mechanism in ringwoodite, Phys. Earth. Planet. Inter., 152, 191-199.

V. Farra, Institut de Physique du Globe de Paris, 4 Place Jussieu, Paris F-75252 cedex, France. (farra@ipgp.jussieu.fr)

L. P. Vinnik, Institute of Physics of the Earth, B. Grouzinskaya 10 , Moscow, 123995, Russia. (vinnik@ifz.ru) 